\title{
Making Sense of Digital Game-Based Learning: A Learning Theory-Based Typology Useful for Teachers
}

\author{
Min Lun $\mathrm{Wu}$ \\ Ohio University, 1 Ohio University, Athens, OH 45701 \\ Tel: 517-775-8897 E-mail: wum@ohio.edu
}

Received: April 18, 2018 Accepted: Sep. 27, 2018 Published: November 1, 2018

doi:10.5296/jse.v8i4.13022 URL: https://doi.org/10.5296/jse.v8i4.13022

\begin{abstract}
Digital game-based learning (DGBL) has gained traction on various educational levels in recent years as educators continue to seek best practices and researchers keep conducting studies to investigate the affordances and constraints of such technology-mediated instruction. This paper discusses the intersections between the historical development of educational digital games and contemporary theories of learning. Resultant from the review, a typology of educational digital games consisting of four genres -- edutainment and educational game applications, serious games, commercial off the shelf and massive multiplayer online role-playing games, and educational game design tools--is devised to help teachers interested in digital games better understand the pedagogical processes and cope with challenges involved in implementing DGBL. The paper concludes with the importance that the implementation of different genres of educational digital games in instruction entails teachers' usage of different pedagogical strategies in accordance with the chosen game genre and opportunities to teach subject area content.
\end{abstract}

Keywords: Digital game-based learning (DGBL), educational technology, teachers, classroom implementation, learning theory 


\section{Introduction}

Digital games have over the years emerged as not only media for entertainment but increasingly an unorthodox agent for delivering information in realms of corporate training, healthcare, politics, advertisement, and for facilitating learning and education in informal and formal settings. Games and gamification have been a repeated theme in the New Media Consortium Horizon Reports that predict upcoming technological trends with time to adoption horizons impactful for teaching and learning in K-12 schools and higher education institutes. The 2014 report stated the growing culture and niche communities around digital games and the ongoing efforts in game research, acknowledging "effectively designed games can stimulate large gains in engagement, productivity, creativity, and authentic learning" (Johnson, Adams Becker, Estrada, Freeman, Kampylis, Vuorikari, \& Punie, 2014, p.42).

The current educational milieu has availed of digital games as venues for promoting motivation, higher level thinking, content specific learning objectives, problem-based learning, and creative inquiry with well-designed games as digital game-based learning (DGBL) incrementally gaining relevance in education (Gee, 2007; Itō, 2010; Prensky, 2006; Salen, 2007; Squire, 2011; Wu, Richards, \& Saw, 2014; Wu, 2018). The intent of the author lies in assisting K-12 teachers to develop the awareness of the differences of game genres and ensuing implications for practicing DGBL. Building on our own prior work (Wu \& Richards, 2014), the researcher created an updated typology of educational digital games and provided not didactic, but pedagogical advice on how to approach DGBL in K-12 classrooms.

To this end, it is useful to define educational digital games. Quintessentially educational digital games are referred to as electronic video games designed first and foremost to facilitate teaching processes in content delivery and outcome assessment, and promote learning objectives while using interactive and multimodal information feeds. Educational digital games operate on digital venues such as dedicated web-based gaming servers, hand-held gaming devices, smart phones, tablets, and game consoles and are distinct from conventional analog-based card and board games, and physical games.

Games and Squire (2011) aptly depicted the historical development of educational digital games in a chronological review that documented the developing trends in the early days of edutainment games, instances of successful repurposing of commercial games for education, and more recently the prominent rise of serious games. Through reviewing prior research that discussed the development of digital games for education (Egenfeldt-Nielsen, 2005; Flynn, Bacon, \& Dastbaz, 2010; Games \& Squire, 2011), the researcher extrapolated four main genres of educational digital games which teachers can consider integrating into curricula.

1. Edutainment Games and Educational Game Applications: Edutainment games are computer and video games created to teach content through engaging players with gameplay and entertainment. The primary target audience of edutainment games are preschool aged children, with a pre-dominant emphasis on areas of mathematics, reading, and science. Edutainment games were popular during the 1990s along with the growing market in multi-media personal computers (Michael \& Chen, 2006). Nevertheless, the influx of edutainment software and games did not find success in formal learning settings and in 
business because these games were created with incomparable quality to commercially produced counterparts and the surge of interest in the Internet (Michael \& Chen, 2006; Squire \& Jenkin, 2003; Zyda, 2005). Consequently, edutainment games became associated with games that were monotone, tedious, and offered almost exclusively repetitious "skill-and-drill" practices (Van Eck, 2006). Examples of edutainment computer games are earlier versions of Math Blaster, Reader Rabbits, Oregon Trail, and Where in the World is Carmen Sandiego.

Accompanying the technological advancements in mobile technology beginning since the late 2000s, a slew of short-form, casual, and edutainment-like games have found a new home among smartphone and tablet computer users. These games are educational applications designed to induce instant gratification and operate on mobile technologies in most cases with low hurdles in gameplay mechanics, knowledge or skills to attract light game players or young children with limited experience in playing complex or long form digital games. Following from the same vein as edutainment games, educational game applications for mobile devices tend to be small in scope and endorse drill and practice, providing players simplistic and repetitious practice to help players pick up content via rote learning. To name a few, Monster Physics, Math Ninja, PBS Kids, Brain Coach, Hangman, Dinosource, Spell Pop, and Motion Math Zoom are instances of popular mobile game applications.

2. Serious Games: The most promising DGBL strategy, according to Van Eck (2015), is "building digital games from the ground up to teach students specific content and skills" (p.18). Nowadays more and more user-friendly game design tools are available to academics and practitioners interested in building games to teach content. Leveraging the ever-growing interest in games, we now have more interdisciplinary design teams comprised of content experts, instructional designers, researchers, and game designers who work together in creating serious games that strike the balance among elements of fun, subject area content, and desirable learning outcomes (Van Eck, 2015, p.18).

In retrospect, the serious game movement launched upon the U.S. Army's 2002 release of a first-person shooter video game America's Army (Susi, Johannesson, \& Backlund, 2007). Serious Games was popularized after the Woodrow Wilson Center for International Scholars founded the Serious Games Initiative. In general, serious games are digital games created to teach and impart information rather than solely to entertain, as Michael and Chen (2006) referred to serious games as "games that do not have entertainment, enjoyment, or fun as their primary purpose" (p. 21). However not to preclude serious games from being entertaining, these games instead serve the main purpose of facilitating awareness, training, and education.

Serious games refer to digital games created based on real-life models, systems or workable simulations and used on the Internet, personal computers or video game consoles for purposes of healthcare, public policy, training, science, corporate management, advertising, education, or simulation. Michael and Chen (2006) stated that serious games encompass the same goals as edutainment games but expand beyond teaching memorization and facts to include teaching, training, and informing at all ages to help game players acquire new 
knowledge or skills. Corti (2006) stated that the motivational power of serious games is what first made game-based learning appealing to training and developing professionals. However, DGBL entails more than using fun as a means to entice learners. Compared to commercial video games, Zyda (2005) argued that serious games embodied more than just story, art, and software to include the element of pedagogy that attempts to educate and impart knowledge or skills, thereby making games serious. Examples of serious games are three-dimensional aviation and navigation simulators, history role-playing game Playing History, the military campaign simulation America's Army, the environmental preservation game Wolf Quest, and the healthcare game Remission 2and Quest for the Code.

3. Commercial Off-The-Shelf (COTS) Strategy/Simulation Games and Massive Multiplayer Online Role-Playing Games (MMORPGs): Van Eck (2006) advocated usage of COTS games for teaching because of their practicality and "this approach is currently the most cost-effective...in terms of money and time and can be used with any domain and any learner" (p.22). He contended that this approach is gaining acceptance and that the adoption of COTS games for classroom teaching would maximize quality by "leaving the design of game play up to game designers and the design of learning up to teachers" (p.22). Increasing efforts had been exerted by researchers and educators to examine the educational rendering of digital games in the classroom by using games originally produced for entertainment and commercial purposes (Charsky \& Barbour, 2010; Foster \& Mishra, 2009; Squire, 2005; Werner, Denner, Campe, Kawamoto, 2012; Wu, 2018). Corti (2006) stated that, "simulations and role playing are two key genres of entertainment-oriented games that many people deem to be particularly appropriate for adoption as training tools" (p. 2). Simulated environments, systems, and realistically recreated role play scenarios allow player learners to experience things otherwise too risky, expensive, or physically impossible to achieve in the real-world context (Corti, 2006). Foster, Katz-Buonincontro, and Shah (2011) used four video games, including a simulation game Rollercoaster Tycoon, and documented the integration process of DGBL in an urban high school setting to develop students' math and science skills. These studies were tenable and provided practical instances documenting teachers' use of game-based learning activities and teaching strategies to link game play to broader course learning objectives while acknowledging difficulties in such implementations. Examples of COTS games are simulation and strategy-based games and massively multiplayer online role playing games (MMORPGs) such as Age of Empires, SimCity, Roller Coaster Tycoon, Civilization, World of Warcraft, and Zoo Tycoon. These games are most often marked by open and persistent worlds, turn-taking, strategizing moves to counteract moves made by artificial intelligence or player-controlled enemies, a quest-based guild system, multi-player communication, and in-game collaboration. When effectively deployed, the repurposing of COTS games can leverage learning in formal and informal curricular contexts given several advantages including pre-existing familiarity to students, well-designed game features, presentation and effects, and consultation of the resources readily available in online communities or affinity spaces (Charsky \& Mims, 2008; Gee, 2007; Sandford, Uicsak, Facer, \& Rudd, 2006; Squire, 2011; Wu \& Richards, 2014). 
Collectively, research involving the incorporation of COTS games in learning settings emphasized the need for "more detailed examples of classroom use, pointing out the majority of games used in schools are used by teachers that develop an affinity for the games and the associated necessary expertise in their own time" (Sandford et al., 2006, p. 1). Charsky and Mims (2008) emphasized the importance of teachers' mastering of games and the knowledge development as being "invaluable in helping students overcome frustration and troubleshooting any issues that may arise“ (p. 38). For teachers with less familiarity with digital games, guidance in the form of game-based lesson plans would be desirable. To render COTS games for classroom teaching effectively, the bottom line is that teachers initially have to familiarize themselves with the game contents, mechanics and dynamics of the chosen game, and subsequently identify in-game scenarios and features relevant for promoting student learning of subject area knowledge and skills.

4. Educational Game Design Tools: Van Eck (2006) discussed the utilization of game design tools and asserted that this approach placed students in the role of designer and through problem-solving in building games, they learn content. However, this student-design approach would be conventionally limited to the computer science domain and is time-intensive as most students might not have readily available background in coding and programming (Van Eck, 2006).

The process which players go through in learning to navigate entry level game design tools align with the underpinnings of current learning theory where knowledge is socially-constructed and situated in interactive contexts (Gee, 2003; Prensky, 2001). The learning outcomes induced through design-related activities are usually in the form of virtually constructed worlds, playable digital artifacts of functional game environments where core elements such as rules, goals, scoring system, and assets are embedded to create a win state, which is the goal within a digital game. Research done in areas of educational game design concluded that iterative design, play-testing, and game refinement based on peer feedback can lead to player learners' emergent development of creativity, system thinking, problem-solving, computational thinking, and spatial reasoning skills (Denner, Werner, \& Ortiz, 2012; Salen, 2007; Werner et al., 2012; Wu, 2018). Albeit these cognitive skills are not directly tied to formal academic subject area knowledge examined in standardized testing, researchers contended that they are critical $21^{\text {st }}$ century skills necessary for students to navigate successfully in today's borderless world of computing, information, and technology (Gee, 2007; Wing, 2006, 2008). The adoption of educational game design in classroom settings usually requires that the teacher is familiar with or preferably well-versed in essential game elements and the flow of gameplay because very often game design starts from a blank slate. In effect, students will need more design-related guidance and technical support from the teacher, leaving educational game design by comparison a higher hurdle for teachers inexperienced in using games to teach. Examples of entry-level programming tools for teaching and learning about educational game design are App Inventor, Microsoft Kodu, Tynker, Code.org, Gamestar Mechanics, Never Wintry Nights, Storytelling Alice, and Scratch. 
Theories and practices notwithstanding, it is found in research that digital games promote more conceptual, strategic, and procedural learning with less foci on textual and rote learning required by mandated curriculum standards and standardized testing. The discrepancy of learning objectives highlighted by DGBL and standard-based learning could lead to a fallout. As Squire (2006) aptly put, "as video games mature as a medium, the question becomes not whether they will be used for learning but for whom and in what contexts" (p. 27). His statement captured the upswing momentum of DGBL and called for the need for more research focusing on not why but on how games should be used to promote learning at different grade levels in schools (Van Eck, 2006).

In the following section, the researcher provides a purview on potential connections between the design of educational digital games and the development of learning theories with the aim to link learning to gameplay, and to provide rationale for the integration of educational digital games in K-12 classrooms.

\section{Linkage between the Paradigm Shift of Contemporary Theories of Learning and the Historical Development of Educational Digital Games}

The shift of contemporary learning theories in education has paralleled the development of increasingly complicated game design, mechanisms, and effects in digital games (Flynn, Bacon, \& Dastbaz, 2010). In light of the parallels between the evolution of educational video games and accompanying paradigm shift in learning theories, Egenfeldt-Nielsen (2005) identified three generations of educational digital games.

The first generation of educational games, created beginning from 1980sto early 1990s, were "edutainment" games designed with the underlying principle that learning is essentially a behavioristic endeavor. Controlled input and stimuli such as repeated drill and practice were built into edutainment games to affect direct instruction and learning. Edutainment games had been prevalently used in primary school settings to promote directly observable learning. However, most edutainment games were not successful because they were designed with low budgets, overly simplistic rules and effects, and learning objectives that did not support progressive understanding (Michael \& Chen, 2006). Another reason leading to the eventual downfall of edutainment games was the overall low quality compared with commercially produced counterparts.

Beginning in late 1990s, the second generation of educational games was designed following the principles of cognitive learning (Egenfeldt-Nielsen, 2005). These educational games moved away from the focus on stimulus and response/behavior to one on the learner's cognitive skills. Games were designed based on the premise that player learners are not black boxes and they come to play the game with pre-existing knowledge and schemata. The different knowledge bases learners brought into gameplay would interact with the game content to produce differentiated effects on learning. Design considerations in these games subscribed to cognitive constructivism concepts such as scaffolding, chunking, perception, and facilitation. These games aimed to present information and deliver content in a cognitively appropriate format to specific learners. 
In the early 2000 s, the third generation of educational games foregrounded the processes of educational use of digital games. These games introduced a social context that promoted meaningful, creative, socio-culturally interactive learning activities, collaboration, and problem-solving which were core learning concepts from constructivism and situated learning theory (Lave \& Wenger, 1991). When adopting these games, the teacher became the central facilitator adapting digital game experiences to classroom teaching (Gros, 2007) by engaging students in hands-on game-centric activities such as group design and field experience to explore game contents further rather than relying solely on the game itself to impart knowledge. Egenfeldt-Nielsen (2005) observed that most popular educational games included features of adventure, strategy, and simulation. He concluded that there was a tendency in the market to produce games based on the second and third generation learning models, i.e., games designed based on learning principles of cognitive constructivism and social constructivism.

Building on Egenfeldt-Nielsen's work and the intent to expand its scope, the researcher proposes that the fourth wave of educational digital games spawned around late 2000s and early 2010s following the constructionist learning approach (Papert \& Harel, 1991). These games promote active learning in the form of deliberate actions of construction. At its core, the design and creation of game space and artifacts are the main gameplay mechanics. Player learners engaging in the construction of a game rely on creativity and systematic thinking as they test hypotheses and learn from trial and error in designing a functional game space. With practice and over time player learners would develop a designer language and mindset through dialoguing with the game being designed and game-testers who provide feedback (Denner, Werner, \& Ortiz, 2012; Games, 2008, 2010; Hayes \& Games, 2008). Novice game designers were encouraged to take on the role of makers, creators, and designers who can participate to varying degrees in the design process (Salen, 2007; Werner et al., 2012).

In recent years we have observed a rise of augmented reality (AR) and virtual reality (VR) applications that have made inroads on game consoles, tablet computers, and smartphones. Though AR, VR, and mixed reality applications are still at their nascent stage, these emergent technologies are well-positioned to impact education when they are re-purposed for classroom implementation considering their incremental popularity, lowering cost, and perhaps more importantly the next-generation power of immersive gameplay. Web-based and mobile applications such as Aris, Aurasma, Tale Blazers and Pokemon Go could be utilized to augment learning in areas of geocaching, location-based learning, and exercise when appropriated in alignment with curriculum objectives and standards.

To conclude, Egenfeldt-Nielsen (2005) and Flynn et al. (2010) detailed how the shifting theories of learning in turn impacted the trends in the design and gameplay in educational digital games. Flynn and colleagues found that there is "a casual link between the design of video games throughout the past 25 or so years that mirrors the hierarchical nature of theories of learning" (p. 1550). Since the design principle and gameplay of educational digital games paralleled with the development of learning theories, there exists the need for the development of a classification scheme regarding how well certain games, when used for education, can cater to specific pedagogical approaches and learning objectives. 


\section{Macrothink}

Consolidating extant literature and the author's own work, the researcher created a typology by aligning contemporary learning theories with examples of popular educational digital games used in learning contexts (see Figure 1). While some game titles may be categorized under one learning theory, it does not follow that they strictly adhere only to the learning principles imparted by that learning theory. Rather, the researcher acknowledged that the games enumerated in the figure may share commonalities in game features and play mechanics and therefore games could be categorized under more than one learning theory. Below is a synopsis of the four main learning theories guiding the design and characteristics of educational digital games.

1. Behaviorist Theory: This theory focuses on Skinner, Pavlov and Thorndike's observation that humans are biologically wired to learn and learning can be achieved by reinforcing, substituting, or removing external conditions and stimuli (Phillips \& Soltis, 2004). In sum, this theory posits that learning happens best with repeated practices following the pattern of stimulus and response and the evidence of learning is directly observable behaviors.

2. Cognitive Constructivist Theory: This theory concentrates on Chomsky and Dewey's proposition of understanding how the brain takes in information and how it processes and link that information to pre-existing knowledge to solve problems (Flynn et al., 2010, p. 1551). It posits that learning is about individuals constructing and conceptualizing knowledge, and integrating newly acquired information within existing schema.

3. Social Constructivist Theory: This theory focuses on Vygotsky's social aspect of learning, positing that knowledge is formed through individual creation but based and maintained by the social group, culture, or context (Flynn et al., 2010, p. 1551).

4. Constructionist Theory: This theory of learning is connected to experiential learning and posits that teaching is most effective when parts of the learning activity the learner experiences are about constructing a meaningful product (Papert \& Harel, 1991). Thistheory places premium on learning to think systematically and designing a functional game space while faring through tasks related to problem-solving and construction (Games \& Squire, 2011). 


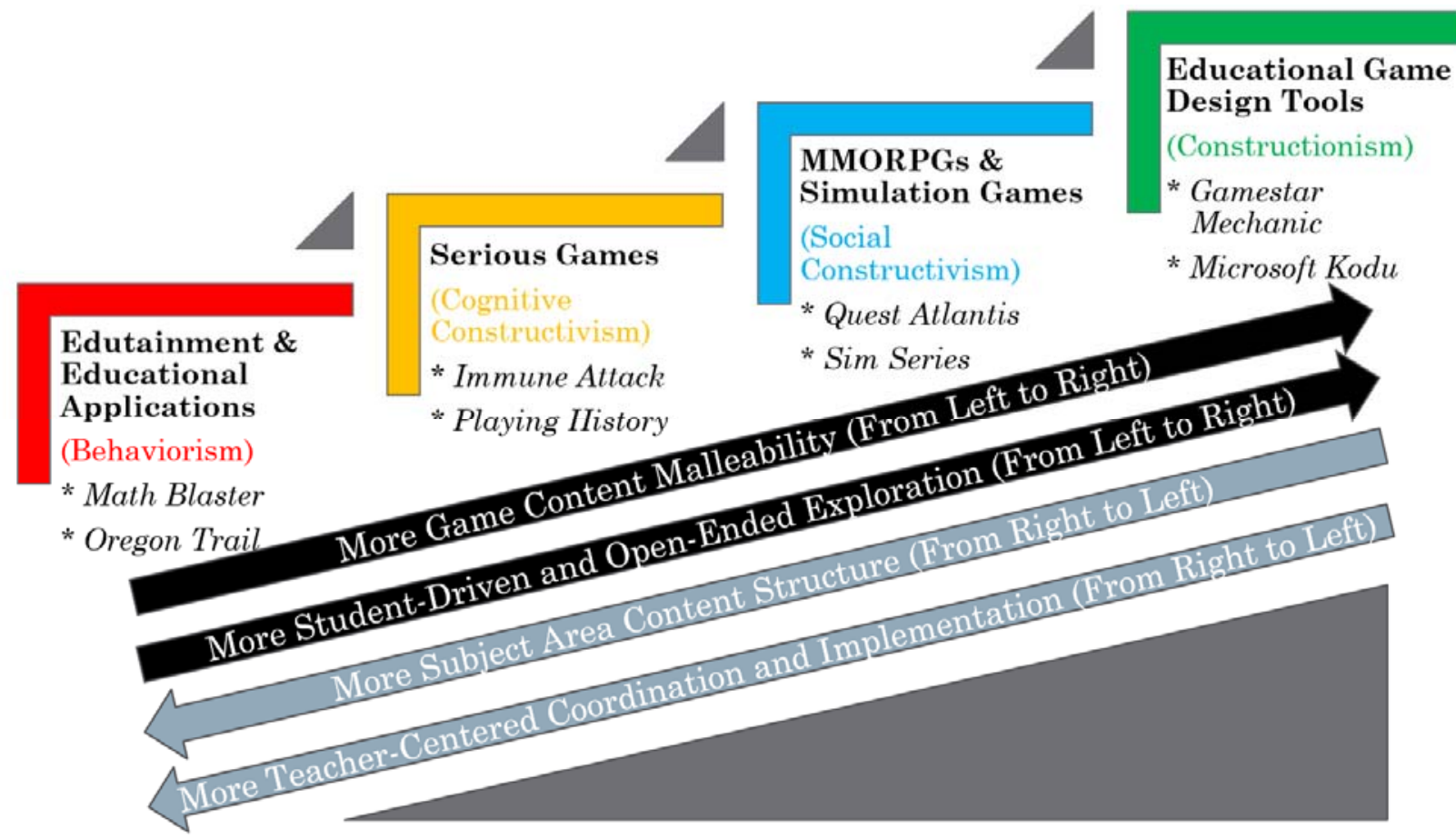

Figure 1. Typology of Educational Digital Games and Corresponding Learning Theories

The proposed typology along with the pointing arrows suggest that these four types of educational digital games vary in terms of the degree on predetermined game content and structure, content malleability, and the types of learning opportunities afforded in accordance with each respective design principle based on different learning theories.

The ladder-like spectrum does not imply strict hierarchy of preference or usability but implicates a trajectory through which teachers may progress (from left to right) when they gain more experience and skills in using digital games for instructional purposes. As such, it is reasonable to assume that edutainment games or serious games tend to be more pre-structured in terms of game content and the subject area knowledge they are going to promote for learning when used in a classroom context. These games are usually more teacher-centered and potentially require less effort on lesson planning or coordination on the part of the teachers because they embody pre-packaged educational contents to be incorporated via a DGBL lesson plan. On the other end of the spectrum, educational game design tools or MMORPGs are less restricted in game structure and allow more flexibility for teachers to tailor teaching strategies to address desired learning objectives. These games are more student-driven because player learners are encouraged to wield creativity and engage in problem-solving through partaking in teacher-scaffolded activities and peer-supported explorations, thereby posing potentially more strenuous and challenging lesson planning and content delivery, technology set-up, and decentralized classroom management style for teachers.

To illustrate concrete examples, when a teacher wants to promote creativity, collaborative learning, and problem-solving (i.e., learning principles of constructivism and constructionism) in subject areas such as science or computer engineering for young adolescents, educational 


\section{Macrothink}

digital games such as MinecraftEdu and Tynker would work best considering they are open-ended and the game play encourages exploratory and discovery learning. Conversely, when a teacher intends to facilitate drill and memorization (i.e., learning principles of behaviorism) among young children, games such as Math Blaster or Reader Rabbits would lend themselves best given these games are more structured and involve repeated practices that foster rote learning and fundamental sensorimotor skills.

Note that some games can share features that can be built on to promote learning objectives in line with multiple learning theories. A game such as Immune Attack or Oregon Trail can be adopted by the teacher to facilitate individual learning in accordance with principles in both cognitive constructivism and behaviorism when scaffolded with appropriate learning activities such as fact worksheets and personal reflections. Similarly, when teachers want to promote both social constructivist and constructionist learning, they can adopt Gamestar Mechanics and carry out DGBL by putting students in collaborative groups, allowing peer play-testing, encouraging social interaction, entertaining feedback, and solidifying student learning by emphasizing the notion that learning and knowledge are the fruition of processes of co-construction.

Overall, a teacher's decision on choosing which type(s) of educational digital games for classroom instruction should depend on sound pedagogical considerations of in-game subject area content, content appropriateness, student age, developmental stages, target learning objectives, individual or group dynamics, available technology infrastructure and resources. Similar to all cases of lesson planning, it is imperative for teachers interested in using DGBL to familiarize themselves with the chosen game(s) before bringing it to real-time classroom implementation. See below Table 1 for reference of educational digital games designed based on the four contemporary learning theories, with corresponding target learning opportunities and befitting age group. 
Table 1. Educational Digital Games, Target Learning Opportunities and Corresponding Learning Theory in Design

\begin{tabular}{|c|c|c|c|c|}
\hline & Behaviorism & $\begin{array}{l}\text { Cognitive } \\
\text { Constructivism }\end{array}$ & $\begin{array}{l}\text { Social } \\
\text { Constructivism }\end{array}$ & Constructionism \\
\hline $\begin{array}{l}\text { Target } \\
\text { Learning } \\
\text { Opportunities }\end{array}$ & $\begin{array}{l}\text { *Memorization } \\
\text { *Drill } \\
\text { *Repetition } \\
\text { *Individual } \\
\text { work }\end{array}$ & $\begin{array}{l}\text { *Individual } \\
\text { information } \\
\text { processing } \\
\text { *Individual } \\
\text { problem-solving }\end{array}$ & $\begin{array}{l}* \text { Group work } \\
* \text { Collaboration } \\
\text { *Co-constructing } \\
\text { and sharing } \\
\text { knowledge }\end{array}$ & $\begin{array}{l}\text { *Learning by } \\
\text { doing } \\
\text { *Systemic } \\
\text { thinking } \\
\text { *Creativity } \\
\text { *Collaborative } \\
\text { problem-solving }\end{array}$ \\
\hline $\begin{array}{l}\text { Target Age } \\
\text { Group }\end{array}$ & K-6 & $6-10$ & $8-12$ & $8-12$ \\
\hline $\begin{array}{l}\text { Suggested } \\
\text { Game Titles }\end{array}$ & $\begin{array}{l}\text { *Math Blaster } \\
\text { *Jeopardy } \\
\text { *Reader } \\
\text { Rabbits } \\
\text { *Oregon Trail } \\
\text { *Where in the } \\
\text { World is } \\
\text { Carmen } \\
\text { Sandiego? } \\
\text { *Dinosource } \\
\text { *Words with } \\
\text { Friends } \\
\text { *Monster } \\
\text { Physics } \\
\text { *Motion Math } \\
\text { Zoom } \\
\text { *Bidge } \\
\text { Constructor }\end{array}$ & $\begin{array}{l}\text { *Life } \\
\text { Preservers } \\
\text { *Immune Attack } \\
\text { *Re-Mission } 2 \\
\text { *Playing } \\
\text { History } \\
\text { *Spore } \\
\text { *Dimension M } \\
\text { *Supercharged! } \\
\text { *Environmental } \\
\text { Detectives } \\
\text { *WolfQuest } \\
\text { *Quest for the } \\
\text { Code }\end{array}$ & $\begin{array}{l}\text { *Civilization } \\
\text { series } \\
\text { *Quest Atlantis } \\
\text { *Roller Coaster } \\
\text { Tycoon series } \\
\text { *SimCity } \\
\text { *Age of Empire } \\
\text { *World of } \\
\text { Warcraft } \\
\text { *Everquest } 2\end{array}$ & $\begin{array}{l}\text { *Gamestar } \\
\text { Mechanics } \\
\text { *Tynker } \\
\text { *MinecraftEdu } \\
\text { *Microsoft Kodu } \\
\text { *Storytelling } \\
\text { Alice } \\
\text { *Scratch } \\
\text { *Code School } \\
\text { *Codea }\end{array}$ \\
\hline
\end{tabular}


Similar to all implementations of educational technologies, it is important to bear in mind that DGBL should not be considered a panacea. Plugging a digital game into classroom instruction does not guarantee students will enjoy the process or that the game will produce satisfying learning outcomes. Depending on desired learning objectives, student age, learning preferences, and technology availability, the contexts for using DGBL vary greatly from case to case. Sandford et al. (2006) called for the differentiation between the types of learning opportunities afforded to teachers by different types of games, and stated that the differentiation would aid the process of coming to a fuller understanding of the potential of using digital games in education (p. 3). The researcher-developed typology of educational digital games answers the call as it serves to sensitize and help teachers understand the four different genres of educational digital games are designed to potentially promote different learning opportunities for students. Teachers should approach the adoption and implementation of each genre of educational digital games thoughtfully and purposively with a corresponding set of instructional objectives, strategies and anticipated learning outcomes.

\section{References}

Charsky, D., \& Barbour, M. (2010). From Oregon Trail to Peacemaker: Providing a Framework for Effective Integration of Video Games into the Social Studies Classroom. In Society for Information Technology \& Teacher Education International Conference, 1, 1853-1860.

Charsky, D., \& Mims, C. (2008). Integrating commercial off-the-shelf video games into school curriculums. Tech Trends, 52(5), 38-44. https://doi.org/10.1007/s11528-008-0195-0

Corti, K. (2006). Games-based Learning; a serious business application. Informe de Pixel Learning, 34(6), 1-20.

Denner, J., Werner, L., \& Ortiz, E. (2012). Computer games created by middle school girls: Can they be used to measure understanding of computer science concepts? Computers \& Education, 58(1), 240-249. https://doi.org/10.1016/j.compedu.2011.08.006

Egenfeldt-Nielsen, S. (2005). Beyond edutainment exploring the educational potential of computer games. Entertainment Software Association. (2012). Retrieved from http://www.theesa.com/facts/

Flynn, R., Bacon, E., \& Dastbaz, M. (2010,). Impact of Learning Paradigms in Games Design: How the Theory of Learning has Influenced the Design of Video Games. In Global Learn Asia Pacific, 2010(1), 1550-1556.

Foster, A. N., \& Mishra, P. (2009). Games, claims, genres \& learning. Handbook of research on effective electronic gaming in education, 1 , 33-50. https://doi.org/10.4018/978-1-59904-808-6.ch002

Foster, A., Katz-Buonincontro, J., \& Shah, M. (2011). Designing a game-based learning course: K-12 integration and pedagogical model. In Society for Information Technology \&

Teacher Education International Conference (Vol. 2011, No. 1, pp. 1477-1483). 
Games, I. A. (2008). Three Dialogs: a framework for the analysis and assessment of twenty-first-century literacy practices, and its use in the context of game design within Gamestar Mechanic. E-Learning and Digital Media, 5(4), 396-417. https://doi.org/10.2304/elea.2008.5.4.396

Games, I. A. (2010). Gamestar Mechanic: learning a designer mindset through communicational competence with the language of games. Learning, Media and Technology, 35(1), 31-52. https://doi.org/10.1080/17439880903567774

Games, A., \& Squire, K. D. (2011). Searching for the fun in learning: A historical perspective on the evolution of educational video games. Computer games and instruction, 17-46.

Gee, J. P. (2007). Good video games + good learning: Collected essays on video games, learning and literacy. New York: Peter Lang. https://doi.org/10.3726/978-1-4539-1162-4

Gros, B. (2007). Digital Games in Education: The Design of game-based learning. Journal of $\begin{array}{llll}\text { Research on } & \text { Technology 23-38. }\end{array}$ https://doi.org/10.1080/15391523.2007.10782494

Hayes, E. R., \& Games, I. A. (2008). Making Computer Games and Design Thinking a Review of Current Software and Strategies. Games and Culture, 3(3-4), 309-332. https://doi.org/10.1177/1555412008317312

Itō, M. (2010). Hanging out, messing around, and geeking out: Kids living and learning with new media. MIT press.

Johnson, L., Adams Becker, S., Estrada, V., Freeman, A., Kampylis, P., Vuorikari, R., \& Punie, Y. (2014). Horizon Report Europe: 2014 Schools Edition. Luxembourg: Publications Office of the European Union, \& Austin, Texas: The New Media Consortium.

Lave, J., \& Wenger, E. (1991). Situated learning: Legitimate peripheral participation. Cambridge, UK: Cambridge University Press. https://doi.org/10.1017/CBO9780511815355

Michael, D. \& Chen, S. (2006). Serious games: Games that educate, train, and inform. Boston, MA: Thomson Course Technology.

Papert, S., \& Harel, I. (1991). Situating Constructionism. Constructionism, Ablex Publishing Corporation: 193-206. Retrieved at http://www.papert.org/articles/SituatingConstructionism.htm

Phillips, D. C., \& Soltis, J. F. (2004). Perspectives on learning. Teachers College Press.

Prensky, M. (2006). Don't Bother Me, Mom, I'm Learning! How Computer and Video Games are Preparing Your Kids for 21st Century Success and how You Can Help!. St. Paul: Paragon House.

Salen, K. (2007). Gaming literacies: A game design study in action. Journal of Educational Multimedia and Hypermedia, 16(3), 301-322. 
Sandford, R., Uicsak, M., Facer, K., \&Rudd, T. (2006). Teaching with games: Using COTS games in formal education. In JISC Innovating eLearning Conference.

Squire, K. (2005). Changing the game: What happens when video games enter the classroom. Innovate: Journal of online education, 1(6).

Squire, K. D. (2006). From content to context: Video games as designed experience. Educational Researcher, 35(8), 19-29. https://doi.org/10.3102/0013189X035008019

Squire, K., \& Jenkins, H. (2003). Harnessing the power of games in education. Insight, 3(1), 5-33.

Squire, K. (2011). Video Games and Learning: Teaching and Participatory Culture in the Digital Age. Technology, Education--Connections (the TEC Series). Teachers College Press. 1234 Amsterdam Avenue, New York, NY 10027.

Van Eck, R. (2006). Digital Game-Based Learning: It's not just the Digital Natives who are Restless. Educause Review, 41(2).

Susi, T., Johannesson, M., \& Backlund, P. (2007). Serious games: An overview.

Van Eck, R. (2015). Digital game-based learning: Still restless, after all these years. Educause Review, 50(6), 13-28.

Werner, L., Denner, J., Campe, S., \& Kawamoto, D. C. (2012). The Fairy Performance Assessment: Measuring computational thinking in middle school. In Proceedings of the 43rd ACM technical symposium on Computer Science Education (pp. 215-220). ACM.

Wing, J. M. (2006). Computational thinking. Communications of the ACM, 49(3), 33-35. https://doi.org/10.1145/1118178.1118215

Wing, J. M. (2008). Computational thinking and thinking computing. Philosophical Transactions of the Royal Society A, 366, 3717-3725. https://doi.org/10.1098/rsta.2008.0118

Wu, M. L., \& Richards, K. (2014). Pedagogical Considerations for the Implementation of Digital Game-Based Learning in the Classroom.In Proceedings of Society for Information Technology \& Teacher Education International Conference 2014. Chesapeake, VA: AACE.

Wu, M. L., Richards, K., \& Saw, K. G. (2014). Examining a Massively Multiplayer Online Role-Playing Game as a Digital Game-Based Learning Platform: Mixed Method Case Study on Motivations for Communicative Language Use. Special Issue on Digital Game-Based Learning in Journal of Computers in the Schools, 31(1-2), 65-83.

Wu, M. L. (2018). Educational Game Design as Gateway for Operationalizing Computational Thinking Skills Among Middle School Students. International Journal of Education Studies, 11(4), 15-28. https://doi.org/10.5539/ies.v11n4p15

Zyda, M. (2005). From visual simulation to virtual reality to games. Computer, 38(9), 25-32. https://doi.org/10.1109/MC.2005.297 